\title{
Virtual University As a Horizon of Higher Education Modernization
}

\author{
M.V. Beilin¹, I.Yu. Soina², Y.A. Dyachenko³, and Yu.A. Semenova ${ }^{2}$ \\ ${ }^{1}$ Belgorod National State Research University, Belgorod, Russian Federation \\ ${ }^{2}$ Kharkiv State Academy of Physical Culture, Kharkiv, Ukraine \\ ${ }^{3}$ Tver State Technical University, Tver, Russian Federation
}

\section{Abstract}

The research aim is to analyze the ontological foundations of virtual education in an information society. Among the methods of research used are analysis, synthesis, abstraction, comparison, interpretation, systematization, classification, conceptualization, structural, functional and prognostic methods. The Virtual University is considered as a networking institution that creates unique opportunities for both spontaneous and purposeful manipulation of human development. It is argued that a virtual university must be built with new values in mind: openness, accessibility, democracy, non-discrimination for people with disabilities and other needs of the individual and society. It is argued that

Corresponding Author:

M.V. Beilin

beilin@bsu.edu.ru

Published: 21 January 2021

Publishing services provided by Knowledge E

(c) M.V. Beilin et al. This article is distributed under the terms of the Creative Commons

Attribution License, which permits unrestricted use and redistribution provided that the original author and source are credited.

Selection and Peer-review under the responsibility of the XXIII International Conference Conference Committee. the formation of a new picture of the world, which assumes the responsibility of mankind to himself Iherself and to nature, the increase of the value of human life, freedom of choice, is also the reason for the formation of new axiological markers that define the virtual university as an information society phenomenon.

The research has fixed that the presence of a virtual knowledge environment, in which the learning process unfolds, gives rise to the need to develop a virtual culture, which is a special form of communication between the education subjects in the process of knowledge production and consumption. Virtual communication is defined as a subspecies of semantic communication, which involves the exchange of both information and knowledge. An information society based on the world information economy (knowledge economy) stimulates the development of a planetary information infrastructure that defines the educational trends of the 21st century. In the information society, economic activity is ensured by the information and communication environment, an integral part of which is education. Along with the virtual economy, the virtual financial system, etc., there are virtual educational phenomena, including a virtual university.

Keywords: virtual university, educational space, global informatics, post-material values, innovation.

\section{Introduction}

The dynamics of socio-cultural transformations are increasingly embracing all spheres of human life and society. Contemporary education is one of the key areas of shaping and managing these changes because of its principal future orientation. Generational 
change is ongoing, which necessitates a constant updating of educational activities, content and forms in accordance with the requirements of the times. The field of education is an important social institution, since the socio-cultural experience is transmitted through the education system. The transformation of the modern planetary society on the path to the information phase inevitably requires qualitative changes in all spheres of its functioning, especially in the field of education. This requirement is due primarily to the dynamic nature of the world economy, the need for rapid retraining and a high level of general and vocational education. The processes of globalization have historically coincided with the rapid development of information technologies, which allowed in the social sciences to speak of a civilizational transition from an industrial society to a post-industrial (information, knowledge) phase of development. Quantitative and qualitative changes in modern civilization require the development of a new type of educational space - an open educational space, or open education. The open education phenomenon is the global trend of pragmatization of all spheres, including education, and the format of an open university is a natural result of such pragmatization. The post-industrial society formation is accompanied by a large-scale projection of economic approaches to other spheres of social life. The commercialization of universitysociety relations has led to the formation of an educational market that stimulates the development of innovative processes to improve the delivery of educational services in accordance with consumer requirements. The use of new information technologies in the formation of a virtual university [3] makes it possible, in turn, to attract new teaching methods in line with the requirements of globalization. In itself, the virtual university not only changes the cultural environment, but also acts as a product of these changes, embodying the basic principles of open education in its own existence. The philosophical and pedagogical aspects of virtual technology in higher education are more relevant than the debate around the development of technological components: whether or not education will lose its humanistic focus through computer-mediated learning. A virtual university must be created with new values in mind: openness, accessibility, democracy, non-discrimination for people with disabilities and other needs of the individual and society. Formation of a new picture of the world, which assumes the responsibility of humanity to itself and nature, the increase of the human life value, freedom of choice are the reasons and the formation of new axiological markers that define the virtual university as a phenomenon of the information society. 


\section{Methodology and Methods}

The methodological foundations of researching the phenomenon of virtual university are based on an interdisciplinary approach, which is conditioned by the requirements of the modern stage of development of the philosophy of education. The basic principles underlying the study of the virtual university as an educational phenomenon are the general scientific principles of objectivity, integrity, historicism and development. Among the methods of research are general philosophical methods - analysis, synthesis, abstraction, comparison, interpretation, systematization, classification, conceptualization, etc. Structural, functional and prognostic methods were also used. Effective were the approaches of postmodern philosophy, which allowed to reveal the essence of virtualization processes in higher education in the conditions of information society. For the implementation of a virtual university idea and the study of the futurological aspects of its further development such methods as comparative, extrapolation, and philosophical antithesis (prediction) have shown the performance.

\section{Results and Discussions}

Virtual University has evolved from post (paper) forms of education, through TV and radio format up to the modern interactive network format, overcoming the overwhelming number of restrictions inherent in the usual university. As a result of this evolution, as of today, we can observe a logical situation where the spread of virtual learning ideas, on the one hand, correlates with the introduction of modern information technology achievements into education, and, on the other hand, with modernization in the context of the convergence of higher education spaces with the business sector, at the intersection which new models of customer relationships in the form of business representatives and universities as their suppliers are emerging [4, p. 240].

In our opinion, the virtual university as a horizon of modernization in higher education in the context of contemporary civilization challenges can be considered as providing the modern consumer demands of educational services on accessibility, flexibility, innovation and orientation to real labor market demands. In more detail, these requirements are as follows: a) accessibility - students want to gain knowledge online; b) flexibility most students want courses to be available at any time, without a fixed schedule that addresses the requirements of working students or simply by allowing them to study at a convenient time; c) innovation - about half of the students would like to receive personalized instruction or online tutoring, considering the experience of teaching in 
traditional audiences less important; d) promoting future employment - universities that directly focus on the education of students prepared for successful work, in demand by industry and / or society are needed [10].

It is a well-known fact that the transition to the post-industrial phase of social development actualized the tendencies of democratization and individualization, which served as an additional factor for the propagation of the virtual education ideas. The modern students require university flexibility, providing space of freedom for realization of their self-realization possibilities; avoidance of potential contradictions with the work schedule, as a large number of virtual students, along with education, are in demand in career progress. Modern universities have begun to adopt new approaches to meet the educational needs of society. The market for educational services and competition in this area has increased significantly, as has the productivity of highly educated workers. Modern universities retrain the university staff in order to teach teachers, the new opportunities of information technology and to introduce asynchronous methods of distance and open learning [5].

Thanks to virtual technologies, education has created favorable conditions for the implementation of lifelong learning ideas, as a virtual university goes beyond its fundamental goals. It was this social inquiry that brought distance education from the periphery of higher education systems, where it had existed for more than a decade, to the forefront of innovative development and directly led to its active implementation in a more sophisticated, computerized form.

Researchers say that their formation was initiated more than a hundred years ago: «As early as the nineteenth century correspondence departments, additional university subunits, and distance education universities have opened their doors to a wide range of clients who, for one reason or another, could not attend classes directly, staying out of traditional universities. The target audience, through distance education, was understood as a separate, special, usually senior cohort in classical universities, as students who were given a «second chance» for one reason or another. Today, millions of people, traditional students and working adults, study using distance learning for a variety of reasons and for many purposes» [8, p. 487].

Thus, we would like to point out that a virtual university is not a university undergoing transformational pressures of the development of technology, but rather a discovery designed to ensure the inherent human rights to education.

In today's post-industrial society, the so-called post-material values (self-realization, freedom, gender equality, etc.) have gained unprecedented urgency, resulting in education being forced to take steps to provide maximum opportunities for a person's desired 
education regardless of physical ability, distance, etc. And the virtual university looks like a social phenomenon capable of meeting the stated needs of modern humanity. I. Anosov notes: «Education as a result can be considered in two plans. The first one is the image of the result, which must be obtained by a specific educational system, and fixed in the form of an educational standard. Modern educational standards include requirements for the traits of a person who completes a certain course of study, for his \her knowledge and skills. Obviously, the content of the standard is a potential representation of a socio-cultural experience that is stored in perfect shape. The second plan is the person who has been trained in a certain system» [1, p. 37].

Against this background, we also seek to be objective in assessing the potential of computer-based educational organizations and to comprehensively consider the phenomenon under study, without artificially distancing themselves from potential threats. The opportunities and resources of global informatics are only marginally used in the process of knowledge production and dissemination - much of it contributes to the flourishing of phenomena that have nothing to do with the knowledge society (meaningless internet «chats», «yellow news», virtual entertainment and «shopping») but dominate global information traffic. Therefore, the knowledge society by itself from the information society will not emerge, since an increase in the amount of information does not necessarily lead to an increase in knowledge. We share our optimism about the utilitarian importance of virtual technologies in education, but we understand that the university, as a special medium for communication and transfer of specific academic knowledge and life experience, cannot be completely replaced by a system of virtual educational practices [4, p. 235]. Indeed, there is a risk of diminishing the quality of learning by minimizing direct contact between the teacher and the student, as education is a particular area in which the experience of interpersonal interaction is extremely important. At the same time, we share the approach according to which a constructive search for ways of implementing the ideas of virtual education should not come down to the level of «demonization» of technologies, and justification of their expediency or impracticality should be impartial [4, p. 234]. Also, in our opinion, one should take note of the following aspect: for the student, the value of learning is the realization of his or her intrinsic interest in learning certain information through a creative and not always easy research path and intellectual effort. Such knowledge can potentially be included in the structure of the individual, they have an individual trajectory of acquisition and special experience of learning. «The transition to a new stage of social memory enables a person to receive educational information from many different sources. Traditionally, they are books, human memory, life experiences, and in the last ten or twenty years 
of the last century, there are also media such as video and audio. With the advent of computers, this list has not only changed but also expanded significantly. Traditional sources began to acquire electronic format, forming one of the facets of virtual reality; electronic textbooks have appeared, in many ways more convenient than paper. Among the innovations that brought virtual reality into the educational process, computer games, distance learning and (or) online learning are very noticeable. Perhaps the main characteristic of the virtual world is that information in it is more accessible and convenient than in traditional sources and, no less important, in virtual reality anyone can become the creator of their own world, a new virtual cultural space. Virtual culture is good, too, because it has many ways of expressing itself, partially or completely impossible in reality» [6]. However, virtual universities may be overwhelmed by the idea of convenience and easy learning, finding effective ways to «monetize» education, etc. that can trigger complicated challenges. In addition, standardization, procedural provision of educational services and minimization of the communicative space also threaten teachers, contradicting the idea of academic freedom of teaching, which is a fundamental component of the pedagogical process in traditional universities [2]. Discussion about the humanistic, ideological role of education is particularly important in the context of discussions about the disadvantages of virtual education, in the context of teaching the humanities, in which the role of direct communication is particularly important. In this regard, K. Edwards, considering the contradictions between the classical idea of a university and a virtual university, notes that most discussions about virtual higher education emerges in the context of technical, professional, natural and social disciplines and, to a lesser extent, in the context of the humanities; at the same time, it is the humanities that initiate discussions concerning threats to the traditional values of universities, updating the problems that emerge when substantiating the relationship between independent work and direct communication with the teacher [7, p. 604].

Thus, we argue that the virtual university responds to the requirements of modern civilization, creating a new type of information field, stimulating learners to self-seek information, its critical comprehension, awareness of their own motivation for learning and result-oriented. Unlike the classic model of the university, the virtual university gives the opportunity to develop in accordance with the dynamic pace of development of society, creating a field for mobility in the full sense of the word: all that a student needs is the availability of a laptop computer and communication with the Internet. A virtual university creates the conditions for the formation of intellectual personalities, the ability to seek and acquire knowledge independently, to make decisions and to apply what has been learned in practice. With easy access, such a learning model can 
ensure that adults are widely involved in the acquisition of this knowledge and applied to the benefit of individuals as well as the state and society in whole.

Organizing an open educational space with the help of a virtual university is naturally regarded as a complex action that should provide nationwide access to educational resources through the widespread introduction and use of educational technologies for distance education. On this basis, citizens create the conditions for the most complete exercise of their right to education, which in its structure and quality meets the requirements of modern economic and civil society development.

Virtual universities have a broad base for creation and successful operation. For example, institutions that have historically operated in the field of open and distance education may be the basis for them; traditional educational institutions that do not have the experience of distance education and thus wish to reduce the cost of education; traditional educational institutions that wish to improve the quality of educational services, which in turn will increase the number of students wishing to learn with the use of new information technologies; corporate business sectors that have their own inhouse training programs. The level of a virtual university development is influenced by such factors as: the emergence of new opportunities for the development of learning technologies in connection with the development of new information technologies; decrease in the cost of training for both parties, inversely proportional to the increase of the possible volume of knowledge; the need to objectively improve the quality of teaching and the rapid use of the latest achievements of various branches of science. For example, the successful use of the Moodle Course Management System, a webbased application allows you to create online learning sites and is freely available. This learning platform aims to bring university staff and students together into a single integrated system to create a personalized learning environment. Social constructivism in this case is basically the construction of knowledge by separate groups for each other, during which the creation of a culture of common artifacts with common values takes place. When a person is immersed in culture, they are constantly learning to be a part of it at different levels, to be its creation and at the same time a creator. The use of such technology allows us focusing on the student as a subject of learning, thus appealing to the synergistic concept of education and the development of a dialogical format of learning instead of a monologue presentation of information. Thus, there is a change of roles: each participant in the educational process becomes not only a student but also a teacher. The teacher himself $\backslash$ herself ceases to be the usual source of information. The teacher becomes more a manager of mastering and training processes [9, p. 77]. This 
new information and communication technologies offer impressive opportunities and prospects for their application in the educational process, emphasizing that humanity is on the verge of an educational revolution, as a result of which fundamental changes in all spheres of human life are undergoing. Together with the new social requirements and the new world community, which is formed as a result of the application of these technologies and models of activity, the need for a new level of education that meets the requirements of the information society is created. The new level of education, in turn, requires the creation of a significantly different technology for the acquisition of scientific knowledge, other approaches to teaching and learning. Therefore, it would be a mistake to believe that the use of new information technologies will automatically increase the quality of education, because it requires the appropriate development of particular fields of psychology, didactics and ethics. In order to remain in the forefront of civilizational progress, universities must recognize the existing challenges and get rid of them, to the extent necessary, fascination with academic traditions [8, p. 217]. The use of new virtual space-related education technologies has made it possible to go beyond spatial and temporal dimensions in some way. Providing direct interactive communication between the subjects of the educational process is an undoubted advantage of such a learning system. In view of the rapid advancement of technology and the related development of various technologies, techniques and systems of learning, it is likely that various electronic libraries, virtual universities, remote access laboratories will be the basis for creating a unified educational and scientific environment for the world community. Virtual university is an educational phenomenon that main purpose is the production and dissemination of knowledge and information for educational and training purposes through information and communication technologies. In the conditions of the modern dynamic world and the innovations introduced by informatization into the society, education requires the use of information technologies for educational, training and professional purposes.

\section{Conclusions}

A virtual university should be understood as the educational phenomenon of the information society, whose primary purpose is the production and dissemination of knowledge and information for educational purposes through information and communication technologies. The need to expand the understanding of the virtual university beyond the traditional technocratic approach through the transition to value-anthropological meanings is revealed. 
The study has revealed that higher education needs to rethink the use of information technologies for economic, educational and professional purposes. The development of a new education system aims at intensification, individualization and continuity of education through the implementation of the open education principles. This, in turn, leads to qualitative changes in the educational space of the modern university: the revision of the status of knowledge itself, the modernization of forms and teaching methods, the transformation of university staff's and students' role in the educational and scientific process.

The study has fixed that virtual university has the ability to train many more specialists than standard universities. This is due, in particular, to the lack of the need for a large logistical base and removal of the personnel issue. In fact, this paradigm is based on a radical re-evaluation of the effectiveness of the traditional learning model. Virtual models in education belong to the class of abstract models on which other models are designed.

Virtual education becomes a new way of education, which allows us more successfully creating the conditions for the true disclosure of the human inner potential. Virtual education has considerable epistemological potential, creating an open space for the creation and transfer of knowledge. In the interpersonal relationship of the teacher and the student (pupil) virtual education finally abolishes subject-object communication, proclaiming the primacy of subject-subject relations. That is, education becomes a technological tool for achieving capital, in which universities «reproduce» information resource such as personnel.

\section{References}

[1] Anosov, I. P. (2003). Antropology Factor Yak Sistematici Element OSTO Processes. Pedagogy, Psychology and Medico-Biological Problems of Physical Education in Sports, vol. 12, pp. 36-44.

[2] Beylin, M. V. and Karpets, L. A. (2018, October). Instrumentalna Knowledge in Osti Diyalnosti. Presented at Modern Educational Space: The Transformation of National Models in Terms of Integration, Leipzig, Germany. Riga: Baltija Publishing, Riga, pp.121-124.

[3] Hutnyk, L. M. (2018, October). Ontology of a Virtual University in the Era of Information Technology. Presented at The International Scientific and Practical Conference "Artificial Intelligence: Ethical Problems of Digital Society", Belgorod, Russia. Belgorod: BSTU, pp. 60-70. 
[4] Drucker, P. F. (2007). The Age of the Gap: Guidelines for our Changing Society. Moscow: I. D. Williams LLC, p. 336.

[5] Karpets, L. A. (2015). Without Interruption, it is Revealed in the Context of the Revealed Reality of the Informational Suspension. Practical Philosophy, vol. 1, issue 55, pp. 167-172.

[6] Murtazina, M. S. (2009). Education and Virtual Culture. Bulletin of the Chita State University, vol. 3, issue 54, pp. 213-217.

[7] Edwards, K. (2001). Virtual Versus Classical Universities: Liberal Arts and Humanities. Higher Education in Europe, vol. 26, issue 4, pp. 603-607.

[8] Guri-Rosenblit, S. (2001). Virtual Universities: Current Models and Future Trends. Higher Education in Europe, vol. 26, issue 4, pp. 487-499.

[9] Raschke, C. A. (2003). The Digital Revolution and Coming of Postmodern University. New York: Routledge Falme, p. 129.

[10] HuffPost. (2014). Retrieved January 20, 2020 from https://www.huffpost.com/entry/ rethinking-what-a-traditi_b_5571263. 